Мельников Михаил Васильевич

кандидат социологических наук, доцент кафедры социологии Новосибирского государственного университета экономики и управления, доцент кафедры социологии и массовых коммуникаций Новосибирского государственного технического университета

\section{ОБЩЕСТВЕННОЕ ПРОСТРАНСТВО ГОРОДА И ЕГО ПРИВАТИЗАЦИЯ: АНАЛИЗ СОЦИОЛОГИЧЕСКИХ ПОДХОДОВ [1]}

\section{Аннотация:}

В статье представлены критический обзор и сравнительный анализ социологических подходов к изучению приватизации общественного пространства города. Рассмотрена семантика понятий «общественное пространство», "приватизация" и "приватизация общественного пространства города». Дана оценка общественному значению и социальным последствиям приватизации общественного пространства муниципального образования. Выделены ее формы - «элитная», или приватизация сверху, и низовая; управляемая и спонтанная. Указаны их общие черты и разли чия. Приведены и проанализированы аргументы в поддержку и критика "элитной» и низовой приватизации пространства. Сделан вывод, что в современном городе уменьшаются общая площадь и социальная значимость открытых общественных пространств. Это приводит к ограничению свободных интеракций и коммуникаций между представителями разных социальных групп. Последствиями этого ограничения являются деградация открытых общественных территорий и снижение качества жизни горожан, не имеющих доступа в приватизированные пространства.

Ключевые слова:

город, общественное пространство, приватизация, открытость и доступность общественного пространства, приватизация общественного пространства города, "элитная" и низовая приватизация пространства, управляемая и спонтан ная приватизация пространства.
Melnikov Mikhail Vasilyevich

PhD in Social Science, Assistant Professor, Social Science Department, Novosibirsk State University of Economics and Management, Assistant Professor Social Science and Mass Communication Department, Novosibirsk State Technical University

\section{THE URBAN PUBLIC SPACE AND ITS PRIVATIZATION: THE ANALYSIS OF SOCIOLOGICAL APPROACHES [1]}

Summary:

The article presents a critical review and a comparative analysis of sociological approaches to the study of the privatization of the urban public space. The semantics of the concepts of public space, privatization and privatization of the urban public space is considered. The study estimates the social significance and impact of privatization of the municipality's public space. The paper distinguishes the following forms of privatization: the "elite" one, or privatization from above, and the grassroots one managed and spontaneous privatization. It shows their similarities and differences as well. Besides, the author presents and analyzes the arguments supporting and criticizing the "elite" and grassroots privatization of space. It is concluded that in a modern city the total area and the social significance of open public spaces are reduced. This leads to a restriction of free interactions and communication between representatives of different social groups. The consequences of this restriction are the degradation of open public spaces and the decline in the quality of life of citizens who do not have access to the privatized public spaces.

Keywords: city, public space, privatization, openness and accessibility of public space, privatization of urban public space, "elite" and grassroots privatization of space, managed and spontaneous privatization of space.

Процессы урбанизации и миграции, получившие в последние десятилетия глобальный характер, приводят к увеличению разнообразия городских сообществ и культур. Гетерогенность урбанистических объединений находит выражение в появлении новых движений, конфллктов, эксклюзий и диктует необходимость внесения изменений в управление городским пространством. Происходящие в городах трансформации обусловливают потребность их научного изучения и предложения путей уменьшения остроты новых и старых проблем городского социума. Одно из новых явлений в городской жизни, привлекающее внимание специалистов, изучающих муниципальные образования, в том числе социологов, определяется в научной литературе как приватизация общественного пространства (далее - ПрОП). Источники пробуждения интереса к изучению этого феномена связаны с интересом к социальным фракторам, формам, практикам и последствиям курса правительств ряда стран на приватизацию общественной собственности и других ресурсов и благ в 1980-е гг.

Цель представленной статьи - критический обзор и сравнительный анализ научных работ, посвященных ПрОП города, вышедших с 1993 г. до 2010-х гг. Их авторами выступают не только 
социологи, но и представители других социальных наук. Результаты совместной работы свидетельствуют о том, что курс на развитие междисциплинарного синтеза в социологических исследованиях города является успешным. Развитие концепции ПрОП - выразительный пример усилий по приданию социологии пространства прикладного характера.

Авторы работ, посвященных рассматриваемому объекту, начинают их с семантики понятий общественного пространства и приватизации. М.Э. Споктер разделил определения городского общественного пространства на четыре группы [2]. В первой внимание фокусируется на способности пространства приводить людей с разными ценностями в одно место, находясь в котором они могли бы оказывать друг на друга какое-либо влияние даже неосознанно для себя. Во второй группе терминов пространство трактуется через социальную активность в публичной сфере. Третью группу составляют ответы на вопрос, как доступность городского пространства определяет его публичность. В четвертой группе исследователи работают с дополнительными категориями, чтобы лучше и точнее обрисовать городское общественное пространство.

Другой подход состоит в выделении типов общественного пространства в городах [3, p. 67]. Первый тип включает в себя общественные места коллективной принадлежности, площади и парки. Второй тип - места неформального общения вследствие случайных и временных интеракций: улица, тротуар, общественный транспорт. Третий тип представлен пространствами преднамеренных интеракций - кафе, музеи, салоны. Общей характеристикой всех типов является то, что общественное пространство способно порождать интеракции между разными группами населения - соседями, чужаками, туристами и т. д. Если использование подобного пространства ограничивается какой-либо одной потребностью или доминированием представителей одной из групп, это приводит к уменьшению разнообразия индивидов, которые могут им пользоваться, и ограничению видов публичной жизни.

Л. Межеевская поддерживает тезис о плюрализме, но отмечает, что социальные интеракции в общественном пространстве должны быть согласованы с существующей в данном социуме системой ценностей [4]. Эти слова значимы отсылкой к очень важному тезису. Общественное пространство открыто и доступно не для абстрактных всех, а для условных своих. Открытость и доступность городского общественного пространства являются не абсолютными, а условными. Последнее во многом предопределяет возможность его приватизации.

В.Л. Люк пишет, что термин «общественное пространство, находящееся в частном владении» появился впервые в 1960-х гг. и использовался применительно к общественным пространствам Нью-Йорка [5]. Э. Кирби трактует ПрОП как реструктуризацию городского ландшафта, взаимосвязанными компонентами которой являются недвижимость, финансы, секторы проектирования и строительства и их влияние на муниципальную власть [6]. Приватизация пространства ведет к приватизации социальных отношений, усилению контроля над доступностью пространства. Этот контроль разделяет публику, использующую пространство, на страты. Дж. Кэйден отмечает, что находящаяся в приватизированном пространстве публика оказывается зависимой от воли и желания собственника налагать ограничения на доступ в пространство и на любую дозволенную в нем деятельность [7]. С. Ниссен выделяет шесть степеней доступности общественного пространства в процессе его приватизации [8]. Первичная приватизация выражается в появлении знаков, указывающих на то, какая деятельность не допускается в пространстве, доступ в которое еще открыт. Полная приватизация выражается в возникновении жилых районов, доступ на территорию которых существенно ограничен.

Особое внимание в рассматриваемых работах уделяется анализу общественного значения и социальным последствиям ПрОП города. В основном она оценивается критически. Э. Кирби, М. Кон [9], Ф. Крупа [10], Т. Уивер [11] считают, что ПрОП ведет к возрастанию неравенства и отчуждения в городах, деградации того, что А. Лефевр и Д. Харви назвали «правом на город», утрате социальных идеалов и главных демократических прав. Южноафриканские ученые Т. Раморока и Й. Цеола [12] отметили, что доступность общественных пространств повышает качество жизни. Соответственно, их приватизация останавливает развитие этого потенциала для чернокожего большинства ЮАР, чей доступ в закрытые общественные пространства ограничен. Дж. Немет и С. Шмидт [13] также пишут об отсутствии у тех, кому достаются приватизированные пространства, интереса к состоянию городской среды, расовым и этническим отношениям, общественным делам в целом. Снижение общей площади открытого пространства и появление приватизированных пространств снижают возможности свободного обмена мнениями для людей, принадлежащих к разным группам.

Еще один результат приватизации пространства - это усиление классовой и расовой сегрегации. Польский исследователь К. Квятковский рассматривает ПрОП как узурпирующее присвоение [14]. Созданная им классификация таких присвоений примечательна тем, что привати- 
зацией пространства как его узурпацией занимаются не только представители «элиты». Узурпацию, состоящую в присвоении пространств частными инвесторами в форме частных пространств публичных гипермаркетов и жилого имущества, автор называет функциональной узурпацией. Футбольные фанаты и молодежные шайки, разделившие город на контролируемые ими зоны, осуществляют культурную и криминальную узурпацию.

Подход К. Квятковского позволяет увидеть, что приватизация пространства города может происходить не только «сверху», т. е. со стороны экономических «элит», но и «снизу», т. е. в буквальном смысле со стороны представителей низовых и во многом маргинализированных и девиантных групп молодежи. ПрОП снизу осуществляется также уличными торговцами и бездомными.

Во Вьетнаме [15] и Мексике [16] уличная торговля и другие виды подобного бизнеса представляют собой стихийную и низовую приватизацию общественного пространства. Она осуществляется представителями бедных социальных классов, не имеющими профессиональной квалификации и официальной занятости. М. Бергамаски, М. Кастриньяно и П. де Рубертис [17] на примере Болоньи показали, как местные бездомные переносят в общественное пространство города частные дела, превращают улицу и площадь в домашнее пространство.

Низовая ПрОП имеет много общего с так называемой «элитной» приватизацией. В обоих случаях мы видим попытки использовать общественное благо, каким является открытое и доступное пространство, в частных интересах. В обоих случаях эти попытки осуществляются способами, вызывающими критическую реакцию со стороны тех, кто оказался свидетелями приватизации и кому она причинила неудобство. В обоих случаях процесс открыт для посторонних. В обоих случаях приватизацию проводят представители разных социально-классовых меньшинств - господствующего и депривированного. Основные отличия низовой приватизации от «элитной» состоят в том, что превращение улицы из места прогулок в базар, двор частного дома и домашнее пространство делает, как считают критики, внешний вид пространства неухоженным, несовременным, непривлекательным для крупных инвесторов и девелоперов, а нередко и небезопасным для благополучных горожан. Кроме того, она является спонтанной, тогда как «элитная» - управляемой. Еще одно отличие обнаруживается в том, что низовая приватизация нередко выступает как практика, не согласованная с местными властями. Возникновение закрытых жилых районов также может вызывать критику, но подобные действия предпринимаются на основе достигнутого с городской властью согласия. Не следует исключать и того, что чиновники и полицейские преследуют уличных торговцев и бездомных как представителей социально чуждого им класса, открыто демонстрирующих то, что буржуазная мораль стремится скрыть от посторонних глаз.

Иначе относятся представители местной власти к «элитной» приватизации. Во-первых, она осуществляется для членов социально близких классов. Во-вторых, ее открытость весьма условна: посторонний глаз видит заборы «элитных» жилых районов, но не то, что они скрывают. В-третьих, она рассматривается власть имущими как механизм, посредством которого возможно снижать фринансовые расходы городского бюджета, перекладывая часть их на структуры, управляющие закрытыми жилыми сообществами, бороться с преступностью, дорожными заторами, плохим санитарным состоянием зеленых и общественных зон.

Критическое отношение к ПрОП не мешает исследователям обращать внимание на иные стороны ее значения для города и муниципального управления. Дж. Фрэзер, Дж.Т. Бэзуин и Дж. Хорнбергер [18] отмечают, что быстрое распространение в конце XX в. закрытых жилых районов и сообществ, находящихся в ведении частных ассоциаций, является важным показателем широких социальных трансформаций. Они перекраивают городской ландшафт в направлениях, которые все больше привязывают судьбу местных жилищных рынков к глобальным волнам капитала. О глобализации как катализаторе возникшего в эпоху индустриальной революции движения в сторону усиления частного пространства пишет О. Ташкин Эртен [19]. Изменения в способности государства и общественного сектора поддерживать работу служб, обеспечивающих общественные потребности, сущности и функциях экономики и культуры выступают влиятельными факторами трансформации городского опыта и движения общественной жизни в частные пространства и сфреры. О. Ташкин Эртен сделал вывод, что ПрОП ведет к замене публичной сферы корпоративной.

Так считает и Э. Кирби [20]. Современный город - это город, в котором общественное пространство имеет меньшее значение, а частные корпоративные территории становятся нормой. Здесь идут на убыль свободные социальные интеракции. Однако к этому не стоит относиться как к социальной катастрофе и политическому преступлению, как это делают Й. Копель и К. Навратек [21]. Э. Кирби подчеркивает, что авторы интерпретаций приватизированных пространств, рассматривающие их в терминах антиутопий и катаклизмов, обманывают сами себя. Во-первых, по причине того, что они используют идеализированные понятия человеческой и коллективной интеракции. Во-вторых, потому что смешивают два разных явления: человеческую интеракцию и 
генерацию идей, которые способствуют публичным дебатам. В свою очередь, анализируя аргументы критиков приватизации пространства в США, К. Дэй утверждает, что критика основана на дебатах о том, как определить постмодернистский город [22]. Осмысление возникновения в городе приватизированных пространств с позиций постмодернизма помогает объяснить фрагментацию физического и социального пространства и связать ее с множеством гетерогенных социальных сообществ.

Общий результат изучения ПрОП города может быть представлен следующим образом. Ее лидирующая концептуализация тесно связана с изучением и критическим отношением к приватизации общественной собственности и социальных благ. Внимание исследователей сосредоточено главным образом на управляемой, хотя во многом постфактум, приватизации, которая осуществляется сверху представителями городских публичных властей и делового истеблишмента. Основная критика такой ПрОП состоит в том, что ее инициаторы отдают приоритет индивидуальным интересам, а не общему благу, особенно в планировании и пространственном развитии. На этом фоне менее заметным видится внимание социологов к спонтанной низовой приватизации общественного пространства, хотя ее появление часто обусловлено приватизацией сверху. Торгово-развлекательные моллы приводят к маргинализации мелких торговцев, а джентрификация способствует увеличению числа бездомных. Низовую приватизацию можно рассматривать как протестный ответ городских низов верхам, данный в форме не революционного выступления, а зримого нарушения господствующих буржуазных норм и ценностей в области социального контроля и управления городом и его общественным пространством.

Применение концепта ПрОП позволяет увидеть современный городской социум как пространство, в котором доминируют частные, корпоративные и классовые интересы, происходит «очастнивание» управления жилыми районами. Исследование приватизации пространства не может обойтись без изучения заинтересованности в ней представителей городской власти. Необходимо выявить мотивы и движущие силы ПрОП на уровне локальных действующих лиц и групп.

\section{Ссылки и примечания:}

1. Статья подготовлена при поддержке РФФИ, грант № 16-03-00348.

2. Spocter M.A. The "silent" privatisation of urban public space in Cape Town, 1975-2004 [Электронный pecypc]. URL: http://etd.uwc.ac.za/xmlui/bitstream/handle/11394/1690/Spocter_MA_2005.pdf?sequence=1 (дата обращения: 05.09.2017)

3. Tonkiss F. Space, the City and Social Theory: Social Relations and Urban Forms. Cambridge (Mass.) ; Malden, 2005.

4. Mierzejewska L. Appropriation of public urban space as an effect of privatization and globalization // Questions geographical. 2011. Vol. 30, no. 4. P. 39-46.

5. Luk W.L. Privately Owned Public Space in Hong Kong and New York: The Urban and Spatial Influence of the Policy [Электронный ресурc]. URL: http://newurbanquestion.ifou.org/proceedings/5\%20The\%20Transformation\%20of\%20Urban\%20Form/full\%20papers/d056_luk_winglun_Revised.pdf (дата обращения: 05.09.2017).

6. Kirby A. The production of private space and its implications for urban social relations // Political Geography. 2008. Vol. 27. P. 74-95.

7. Kayden J.S. Privately own public space: The New York City experience. N. Y., 1998.

8. Nissen S. Urban Transformation: From Public and Private Space to Spaces of Hybrid Character // Czech Sociological Review. 2008. Vol. 44, no. 6. P. 1129-1149.

9. Kohn M. Brave new neighborhoods: The privatization of public space. N. Y. ; L., 2004.

10. Krupa F. The Privatization of Public Space. The State of the Public Realm [Электронный pecypc]. URL: http://www.simpleis-beautiful.org/fredek/pps.html (дата обращения: 05.09.2017).

11. Weaver T. The Privatization of Public Space: The New Enclosures [Электронный ресурс] : APSA 2014 Annual Meeting Paper. URL: https://ssrn.com/abstract=2454138 (дата обращения: 05.09.2017).

12. Ramoroka T., Tsheola J. Gated communities and the privatization of public spaces in urban South Africa: Democratic social integration or exclusion? // Journal of Geography and Regional Planning. 2014. Vol. 7, no. 4. P. 58-68.

13. Nemeth J., Schmidt S. The privatization of public space: modeling and measuring // Environment and Planning B: Planning and Design. 2011. Vol. 38. P. 5-23.

14. Cit. ex: Mierzejewska L. Op. cit.

15. Kürten S. The Transformation of Public Space in Hanoi // Asien. 2008. Vol. 108. S. 67-79.

16. The End of Public Space in the Latin American City? Memoria of the Binational Conference / G.A. Jones, P.M. Ward, et al. Austin, 2004.

17. Bergamaschi M., Castrignanó M., De Rubertis P. The homeless and public space: urban policy and exclusion in Bologna // L'économie politique du 'care'. Entre continuiré et changement. 2014. Vol. 51.

18. Fraser J., Bazuin J.T., Hornberger G. The privatization of neighborhood governance and the production of urban space // Environment and Planning A. 2016. Vol. 48, iss. 5. P. 844-870.

19. Taşkin Erten Ö. Questioning the privatization of public space: The "publicness" of shopping centers [Электронный ресурс]. URL: http://openaccess.iyte.edu.tr/bitstream/handle/11147/2899/413585.pdf?sequence=1 (дата обращения: 05.09.2017).

20. Kirby A. Op. cit.

21. Cit. ex: Mierzejewska L. Op. cit.

22. Day K. Introducing Gender Into the Critique of Privatized Space // Journal of Urban Design. 1999. Vol. 4, no. 2. P. $155-178$. 


\section{References:}

Bergamaschi, M, Castrignanó, M \& De Rubertis, P 2014, 'The homeless and public space: urban policy and exclusion in Bologna', L'économie politique du 'care'. Entre continuiré et changement, vol. 51.

Day, K 1999, 'Introducing Gender Into the Critique of Privatized Space', Journal of Urban Design, vol. 4, no. 2, pp. $155-178$. https://doi.org/10.1080/13574809908724444.

Fraser, J, Bazuin, JT \& Hornberger, G 2016, 'The privatization of neighborhood governance and the production of urban space', Environment and Planning A, vol. 48, iss. 5, pp. 844-870. https://doi.org/10.1177/0308518x15621656.

Jones, GA \& Ward, PM (et al.) 2004, The End of Public Space in the Latin American City? Memoria of the Binational Conference, Austin.

Kayden, JS 1998, Privately own public space: The New York City experience, New York.

Kirby, A 2008, 'The production of private space and its implications for urban social relations', Political Geography, vol. 27, pp. 74-95. https://doi.org/10.1016/j.polgeo.2007.06.010.

Kohn, M 2004, Brave new neighborhoods: The privatization of public space, New York, London. https://doi.org/10.4324/9780203495117.

Krupa, F 2017, The Privatization of Public Space. The State of the Public Realm, viewed 05 September 2017, $<$ http://www.simple-is-beautiful.org/fredek/pps.html>

Kürten, S 2008, 'The Transformation of Public Space in Hanoi', Asien, vol. 108, pp. 67-79.

Luk, WL 2017, Privately Owned Public Space in Hong Kong and New York: The Urban and Spatial Influence of the Policy, viewed 05 September 2017, <http://newurbanquestion.ifou.org/proceedings/5\%20The\%20Transformation\%20of\%20Urban\%20Form/full\%20papers/d056_luk_winglun_Revised.pdf>.

Mierzejewska, L 2011, 'Appropriation of public urban space as an effect of privatisation and globalisation', Questions geographical, vol. 30, no. 4, pp. 39-46. https://doi.org/10.2478/v10117-011-0036-7.

Nemeth, J \& Schmidt, S 2011, 'The privatization of public space: modeling and measuring', Environment and Planning B: Planning and Design, vol. 38, pp. 5-23. https://doi.org/10.1068/b36057.

Nissen, S 2008, 'Urban Transformation: From Public and Private Space to Spaces of Hybrid Character', Czech Sociological Review, vol. 44, no. 6, pp. 1129-1149.

Ramoroka, T \& Tsheola, J 2014, 'Gated communities and the privatization of public spaces in urban South Africa: Democratic social integration or exclusion?', Journal of Geography and Regional Planning, vol. 7, no. 4, pp. 58-68. https://doi.org/10.5897/jgrp2013.0396.

Spocter, MA 2017, The "silent" privatisation of urban public space in Cape Town, 1975-2004, viewed 05 September 2017, $<$ http://etd.uwc.ac.za/xmlui/bitstream/handle/11394/1690/Spocter_MA 2005.pdf?sequence=1>.

Taşkin Erten, Ö 2017, Questioning the privatization of public space: The "publicness" of shopping centers, viewed 05 September 2017, <http://openaccess.iyte.edu.tr/bitstream/handle/11147/2899/413585.pdf?sequence=1>

Tonkiss, F 2005, Space, the City and Social Theory: Social Relations and Urban Forms, Cambridge (Mass.), Malden.

Weaver, T 2017, The Privatization of Public Space: The New Enclosures: APSA 2014 Annual Meeting Paper, viewed 05 September 2017, <https://ssrn.com/abstract=2454138>. 